\title{
Observational Study of Centerline Rumble Strips in Puerto Rico: PR-114 Case Study
}

\author{
Benjamín Colucci PhD, P.E ${ }^{1}$, and Yanira Rivera, BSCE ${ }^{1}$ \\ ${ }^{1}$ University of Puerto Rico - Mayagüez, Puerto Rico, benjamín.colucci1@upr.edu, yanira.rivera4@upr.edu
}

\begin{abstract}
Two-lane, two-way rural roads have been shown to have the highest incidence of fatal and injury crashes [1]. The focus of this research is to study the effectiveness of centerline rumble strips on PR-114, a rural two-way two-lane road treated from kilometer 7.6 in Hormigueros to kilometer 14.6 in San Germán, the first to be treated with this safety countermeasure. The research will help determine the countermeasure's potential for further implementation on the Puerto Rico highway network. The methodology includes a comprehensive literature review on centerline rumble strips, its policies, standards, and guidelines in all fifty states, before-and-after studies, and an observational analysis of PR-114. Preliminary conclusions suggest a tendency for speeding on the segment despite the $56 \mathrm{~km} / \mathrm{hr}(35 \mathrm{mi} / \mathrm{hr})$ posted speed limit. Some signs and other roadside appurtenances cannot be seen due to high roadside vegetation leaving road users with less perception-reaction time. The study also suggests warning signs be placed prior to the narrow bridges and hidden driveways located along the roadway. Overall centerline rumble strips are an effective treatment.
\end{abstract}

Keywords-Centerline Rumble Strips, CLRS, Rumble Strips, Safety Countermeasures.

Digital Object Identifier (DOI): http://dx.doi.org/10.18687/LACCEI2015.1.1.282

ISBN: 13 978-0-9822896-8-6

ISSN: $2414-6668$

13 ${ }^{\text {th }}$ LACCEI Annual International Conference: “Engineering Education Facing the Grand Challenges, What Are We Doing?” July 29-31, 2015, Santo Domingo, Dominican Republic ISBN: 13 978-0-9822896-8-6

ISSN: $2414-6668$

DOI: http://dx.doi.org/10.18687/LACCEI2015.1.1.282 


\title{
Observational Study of Centerline Rumble Strips in Puerto Rico: PR-114 Case Study
}

\author{
Benjamín Colucci PhD, P.E ${ }^{1}$, Yanira Rivera, BSCE ${ }^{2}$ \\ ${ }^{1}$ University of Puerto Rico - Mayagüez, Puerto Rico, benjamín.colucci1@upr.edu \\ ${ }^{2}$ University of Puerto Rico - Mayagüez, Puerto Rico, yanira.rivera4@upr.edu
}

\begin{abstract}
Two-lane, two-way rural roads have been shown to have the highest incidence of fatal and injury crashes [1]. The focus of this research is to study the effectiveness of centerline rumble strips on $P R-114$, a rural two-way two-lane road treated from kilometer 7.6 in Hormigueros to kilometer 14.6 in San Germán, the first to be treated with this safety countermeasure. The research will help determine the countermeasure's potential for further implementation on the Puerto Rico highway network. The methodology includes a comprehensive literature review on centerline rumble strips, its policies, standards, and guidelines in all fifty states, before-and-after studies, and an observational analysis of PR-114. Preliminary conclusions suggest a tendency for speeding on the segment despite the $56 \mathrm{~km} / \mathrm{hr}(35 \mathrm{mi} / \mathrm{hr})$ posted speed limit. Some signs and other roadside appurtenances cannot be seen due to high roadside vegetation leaving road users with less perception-reaction time. The study also suggests warning signs be placed prior to the narrow bridges and hidden driveways located along the roadway. Overall centerline rumble strips are an effective treatment.
\end{abstract}

Keywords-Centerline Rumble Strips, CLRS, Rumble Strips, Safety Countermeasures.

\section{INTRODUCTION}

There are constant efforts in creating safer roadways. Rural roads are statistically shown to have the highest number of fatalities. Two-lane, two-way rural roads have been shown to have the highest incidence of fatal and injury crashes [1]. In 2010 , it was reported that 19 percent of the US population lived in rural areas, however 55 percent of total traffic fatalities occurred in these areas. [2] More recently, in 2013 there were 32,719 total motor vehicle traffic crash fatalities of which 54 percent occurred on rural highways [3][4]. These roads are susceptible due to their higher speeds, long tangents, horizontal and vertical curves, poor or no illumination and roadside characteristics. Furthermore relatively large distances from rural roads to urban medical trauma centers imposes an additional burden on first responders to high severity crash patients.

Puerto Rico is no exception to these rural road crash statistics where rural roads are the most frequent setting for crash fatalities. According to the 2014-2018 Puerto Rico Strategic Highway Safety Plan (hereon referred to as PRSHSP), about two-thirds of all run-off-road crashes occurred on dry pavement conditions, and in 2013, 41 percent of all fatalities are a result of roadway departure crashes [4]. Roadway departure crashes are also referred to as run-off-the road crashes, ROR. Table 1 depicts the ROR fatalities as a percentage of the total number of fatalities from 2009-2013. Roadway departure crashes was the crash type identified as one of the nine major emphasis areas of the PR-SHSP. The most common contributing circumstances noted for the cause of these type of collisions were "driver lost control" and "exceeded speed limit". The National Highway Traffic Safety Administration (NHTSA) defines a roadway departure crash in which a vehicle crosses an edge line, a centerline, or leaves the traveled way including vehicles that ROR (right or left), crossed the centerline or median, went airborne, or hit a fixed object [3]. The PR-SHSP attributes the increase in fatal crashes from 2009 to 2013 to behavioral factors such as distracted and aggressive driving [4]. Driver fatigue, drowsiness, and texting are also contributing factors to these crash types. In order to reduce the number of fatalities it is important to implement corrective safety measures to the roads.

TABLE I

PuERTo Rico ROR CRASH FATALITIES CRASH STATISTICS FROM 2009-2013, DATA SOURCE: 2014-2018 PR-SHSP

\begin{tabular}{|c|c|c|c|}
\hline YEAR & $\begin{array}{c}\text { ROR CRASH } \\
\text { FATALITIES }\end{array}$ & $\begin{array}{c}\text { TOTAL CRASH } \\
\text { FATALITIES }\end{array}$ & $\begin{array}{c}\text { \% ROR CRASH } \\
\text { FATALITIES }\end{array}$ \\
\hline 2009 & 130 & 365 & $35.6 \%$ \\
\hline 2010 & 132 & 340 & $38.8 \%$ \\
\hline 2011 & 129 & 361 & $35.7 \%$ \\
\hline 2012 & 136 & 366 & $37.2 \%$ \\
\hline 2013 & 141 & 344 & $41.0 \%$ \\
\hline
\end{tabular}

Centerline rumble strips (CLRS) are considered to be an effective and low-cost countermeasure used to reduce the number and severity of head-on, opposite direction sideswipe, and single vehicle ROR fatal and injury crashes. Head-on crashes are defined as crashes where the front of a vehicle hits the front of the other vehicle traveling in the opposite direction. An opposite-direction sideswipe crash occurs when two vehicles traveling opposite directions scrape one another. The target drivers include distracted, drowsy, or inattentive drivers who cross the centerline. It is also a navigational aid in fog, or blinding rain [5]. The rumble strips in most cases are located below the centerline striping and are also referred to as centerline rumble stripes. In 2013, the installation of CLRS was completed on highway PR-114 to address the high incidence of roadway departure crashes. This is the first time that this corrective safety measure is implemented in Puerto Rico.

There are 4 different types of CLRS: formed, raised, rolled, and milled, being the most commonly used. These CLRS are designed similarly to shoulder rumble strips, in which the grooves milled along the centerline cause vibration and noise alerting the driver to get back into their travel lane,

$13^{\text {th }}$ LACCEI Annual International Conference: “Engineering Education Facing the Grand Challenges, What Are We Doing?” 
Fig. 1. Before this safety measure is further implemented, it is important to see if this countermeasure is effective on Puerto Rico's highways which have distinct characteristics when compared to most of the United States roads where the CLRS have been previously installed and tested.

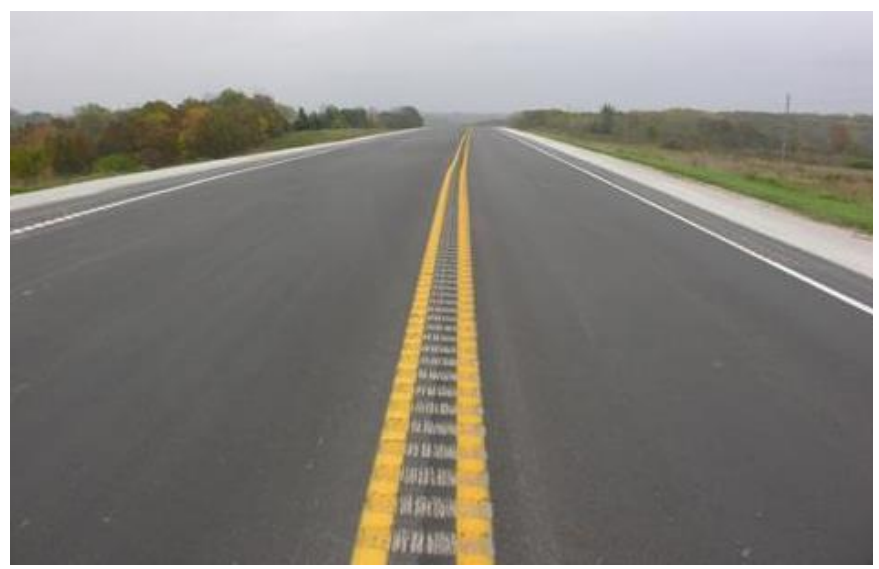

Fig 1 Example of CLRS, Source: safety.fhwa.dot.gov

\section{OBJECTIVES}

The high incidence of aggressive driving on the island is one characteristic that should be taken into consideration when comparing the previous CLRS studies to the possible benefits to Puerto Rico road users. In addition to aggressive driving, the difference in topography, climate, and road user types are several factors worth to consider. Due to the many differences the Island of Puerto Rico holds, compared to the states, it is important to evaluate the CLRS on PR-114, Fig. 2, the only road to date with this safety countermeasure. The primary objective of this study is to evaluate the effectiveness of CLRS as a potential safety countermeasure for the Puerto Rico highway network.

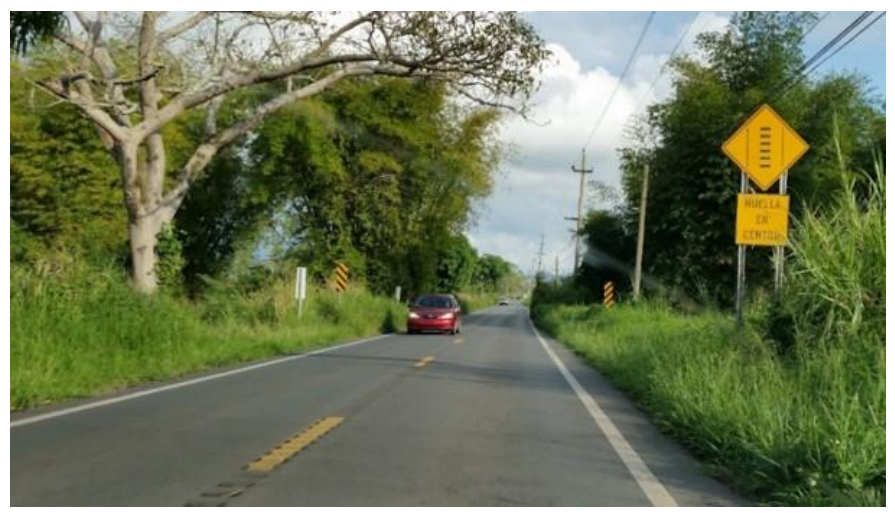

Fig 2 Cross-section of PR-114 Kilometer 12.1 Eastbound

III. SCOPE

The scope of this paper includes a comprehensive literature review and the observational analysis of highway PR-114 within the segment treated with CLRS between kilometers 7.6 situated in the Municipality of Hormigueros and 14.6 in the Municipality of San Germán.

\section{LITERATURE REVIEW}

\section{A. Rural Road Crashes}

Persaud et al. found that sixty percent of all fatal crashes occur on rural roads and ninety percent of those crashes occur on two-lane, two-way rural roads [1]. Of those crashes, 4,500 fatalities per year are collisions where the vehicle crosses the centerline [3]. In a more recent study it was found that of all the cross-over-to-left crashes, $72 \%$ of fatal crashes occurred on rural 2-way, 2-lane undivided roads [6]. In 2013, there were 2,090 head-on and sideswipe (opposite direction) crashes on rural roads, and 6,589 fatalities in the same type of crashes. These numbers show that rural roads continue to have the highest fatal crash occurrence [7].

\section{B. Centerline Rumble Strips, CLRS}

The use of CLRS has increased substantially since its first implementation. In 2003 there were 22 states with installed CLRS and by 2005 that number increased to 46 out of the 50 states [8], [9]. That increase resulted in growing concerns regarding the effectiveness of the safety countermeasure. One study evaluated the effectiveness of the centerline rumble strip on rural two-lane roads on a total of 338 kilometers (210 miles) of road in 7 states before and after CLRS installation. Using the Empirical Bayes method in order to account for regression to the mean bias, and also accounting for factors such as changes in traffic volume, results showed significant reductions in all injury crashes. The study found a 12 percent reduction in all motor vehicle crashes, a 14 percent reduction in all injury motor vehicle crashes, and a 25 percent reduction in frontal and opposite-direction sideswipe crashes involving injuries and overall [1].

\section{Statewide Comprehensive Study}

It would be ideal to standardize the use of CLRS in respect to rumble pattern, dimensions, ADT, lane width, pavement age, pavement depth, area type, and speed limit. In an attempt to achieve this, a comprehensive study was performed looking into the states where the CLRS have been implemented, the type of CLRS used, the rumble dimensions, and whether the state had a policy or a standard. In the 2003,27 out of the 50 states surveyed responded, and out of the 27 states, all used milled CLRS, and 9 had a CLRS policy. The rumble strip dimensions are defined in Fig. 3, a guide provided by the FHWA to help create consistency [5]. 


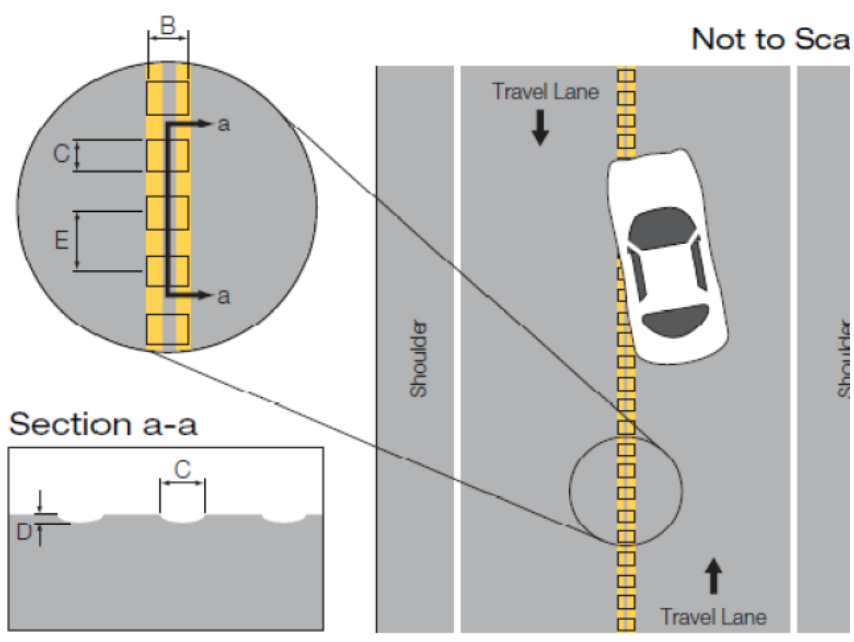

Fig. 3 CLRS Dimensions, Source: FHWA

A similar study was done as part of a comprehensive literature review on the implementation of CLRS. The CLRS pattern type, rumble dimensions, range of speed limits and lane widths are further summarized in Fig. 4. The results are classified according to their corresponding FHWA region.

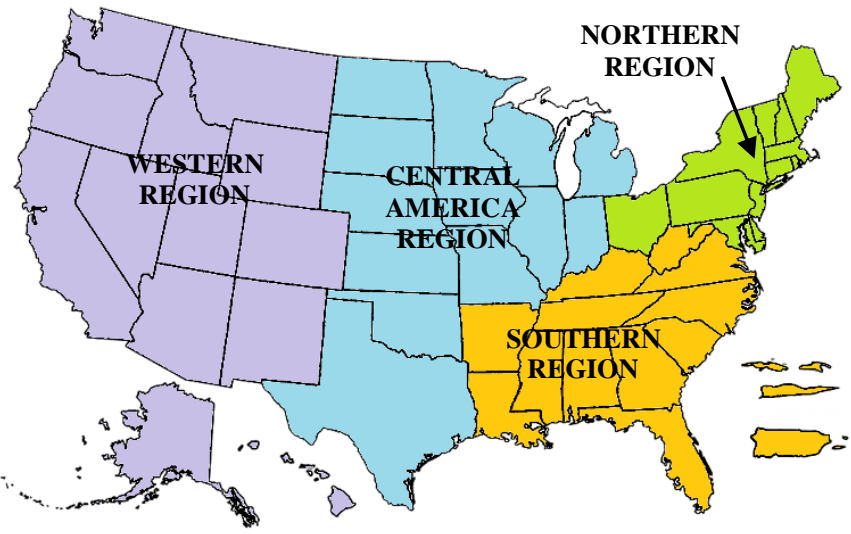

\begin{tabular}{|c|l|}
\hline \multicolumn{2}{|c|}{ WESTERN REGION } \\
\hline & Rumble Dimensions \\
\hline Skip Pattern & Continuous or Alternating \\
\hline Width, cm (in) & $10.16-20.32(4-8)$ \\
\hline Length, cm (in) & $15.24-60.96(6-24)$ \\
\hline Spacing, cm (in) & $30.48-60.96(12-24)$ \\
\hline Depth, cm (in) & $0.95-1.91(3 / 8-3 / 4)$ \\
\hline Posted Speed Limit & $72-80 \mathrm{~km} / \mathrm{hr}(\mathbf{4 5}-50 \mathrm{mi} / \mathrm{hr})^{*}$ \\
\hline Min. ADT & $\mathbf{7 5 0} \mathrm{VPD}$ \\
\hline Min. Lane Width, $\mathrm{m}$ (ft) & $\begin{array}{l}3.66-4.27\left(12^{\prime}-14^{\prime}\right) \text { Lane + Paved } \\
\text { Shoulder }\end{array}$ \\
\hline
\end{tabular}

\begin{tabular}{|c|c|}
\hline \multicolumn{2}{|c|}{ CENTRAL AMERICA REGION } \\
\hline \multicolumn{2}{|c|}{ Rumble Dimensions } \\
\hline Skip Pattern & Continuous or Alternating \\
\hline Width, cm (in) & $12.7 \pm 1.27-17.78 \pm 1.27(5 \pm 1 / 2-7 \pm 1 / 2)$ \\
\hline Length, cm (in) & $20.32-50.8(8-20)$ \\
\hline Spacing, cm (in) & $30.48-60.96(12-24)$ \\
\hline Depth, cm (in) & $0.95-1.59(3 / 8-5 / 8)$ \\
\hline Posted Speed Limit & $72-89 \mathrm{~km} / \mathrm{hr}(45-55 \mathrm{mi} / \mathrm{hr})^{*}$ \\
\hline Min. ADT & $1,500-3,000 \mathrm{VPD}^{*}$ \\
\hline Min. Lane Width, m (ft) & $3.04-3.66(10-12)$ \\
\hline \multicolumn{2}{|c|}{ NORTHERN REGION } \\
\hline \multicolumn{2}{|c|}{ Rumble Dimensions } \\
\hline Skip Pattern & Continuous or Alternating \\
\hline Width, cm (in) & $12.7 \pm 1.27-17.78 \pm 1.27(5 \pm 1 / 2-7 \pm 1 / 2)$ \\
\hline Length, cm (in) & $30.48-45.72(12-18)$ \\
\hline Spacing, cm (in) & $\begin{array}{l}30.48,30.48 \& 60.96, \text { or } 60.96,60.96 \& \\
91.44(12,12 \& 24 \text { or } 24,24 \& 36)\end{array}$ \\
\hline Depth, cm (in) & $0.95-1.27(3 / 8-1 / 2)$ \\
\hline Posted Speed Limit & $56-72 \mathrm{~km} / \mathrm{hr}(35-45 \mathrm{mi} / \mathrm{hr})^{*}$ \\
\hline Min. ADT & 1,500 VPD-3,000 VPD \\
\hline Min. Lane Width, m (ft) & $3.04-3.35(10-11)^{*}$ \\
\hline \multicolumn{2}{|c|}{ SOUTHERN REGION } \\
\hline \multicolumn{2}{|c|}{ Rumble Dimensions } \\
\hline Skip Pattern & Continuous or Alternating \\
\hline Width, cm (in) & $15.24 \pm 1.27-17.78 \pm 1.27\left(6^{1 / 2}-7 \pm 1 / 2\right)$ \\
\hline Length, cm (in) & $15.24-40.64(6-16)$ \\
\hline Spacing, cm (in) & $30.48-60.96(12-24)$ \\
\hline Depth, cm (in) & $1.11-1.59(7 / 16-5 / 8)$ \\
\hline Posted Speed Limit & $72-80 \mathrm{~km} / \mathrm{hr}(45-50 \mathrm{mi} / \mathrm{hr})$ \\
\hline Min. ADT & 400 VPD-12,000 VPD* \\
\hline Min. Lane Width, m (ft) & $3.35-3.66(11-12)$ * \\
\hline
\end{tabular}

Fig. 4 CLRS Standards by FHWA Regions

In creating this database, the assumption was made that the latest policies, guidelines and standards were available from each Department of Transportation website. Then, the specifics of their CLRS procedures were compiled into a table. The terminology for centerline rumble strips varied from state to state. Several states referred to the safety countermeasure as centerline rumble stripes since the traffic paint would be laid over the rumble. New York referred to them as centerline audible roadway delineators (CARDS) due to the noise made when a vehicle passes over the rumbles.

Out of the 50 states and the Commonwealth of Puerto Rico, 44 states were found to have a policy, guideline or standard, however 3 of those guidelines stated that the application of the CLRS to the project was left to the discretion of the traffic or construction engineer. There were 39 states found to have a standard drawing, many of these which complemented the policy. Policies and guidelines are important because they offer a set of parameters that the designer can follow to know whether the highway in question is a good candidate for the safety

$13^{\text {th }}$ LACCEI Annual International Conference: "Engineering Education Facing the Grand Challenges, What Are We Doing?" 
treatment, to know the proper way to design it that would give the best results, and to provide construction guidance. Standard drawings also assist the designer to visualize the policies and guidelines and keep consistency between related projects.

The most common rumble strip application is the milled type which are made by a milling machine and can be done as long as the pavement is in good condition. The application is relatively simple, inexpensive, and provides a great amount of noise and vibration when compared to the raised, rolled, and formed rumble types.

In the state by state comparison, the most common skip pattern was the continuous type following by the alternating pattern. Continuous rumbles provide an equal distance between each rumble throughout the entire application. The tendency was a 30.48 centimeter (12 inch) spacing between rumbles. In several states, it was indicated that a skip in the rumble were to be provided in the case where raised pavement markers were to be installed. In the alternative rumble skip pattern, the pattern would alternate between 2 predetermined distances. The most common was a 60.96 centimeters ( 24 inches) spacing followed by a 91.44 centimeters ( 36 inches) spacing, and so on. A third, and less common skip pattern was the intermittent type, where large gaps of predetermined length would be provided between continuous rumble sections generally for passing vehicles or cyclists.

The dimensions of the rumbles varied from state to state. Several studies have been done to determine which rumble dimensions provide the most effective vibration and noise to the driver, however the results vary depending on the road user, the vehicle, and the pavement. In 35 states, including Puerto Rico, the most common rumble width is 17.78 centimeters ( 7 inches) in width. The most common length is 30.98 centimeters (12 inches) required by 37 percent of the states and Puerto Rico, closely followed by 40.64 centimeters (16 inches) required by 29 percent. The most common depth requirement is 0.95 centimeter ( $3 / 8$ inch) minimum and a 1.59 centimeter ( $5 / 8$ inch) maximum. It is important to note that in many CLRS applications, there were 2 rumble length options depending on whether the application was for a passing or no passing zone.

In addition to the physical characteristics of the rumble, there were several states with roadway characteristic requirements. A minimum speed limit requirement for the application of the CLRS was found to be practiced in 22 states ranging from 56 to $89 \mathrm{~km} / \mathrm{hr}$ ( 35 to $55 \mathrm{mi} / \mathrm{hr}$ ), the most common being $72 \mathrm{~km} / \mathrm{hr}$ (45 $\mathrm{mi} / \mathrm{hr}$ ) followed by $80 \mathrm{~km} / \mathrm{hr}(50 \mathrm{mi} / \mathrm{hr})$. The required minimum ADT required for CLRS installation ranged from 400 to 12,000 vehicles per day, vpd, for the 9 states that had an ADT requirement. Lane width, on the other hand, was given more priority than ADT in centerline applications with a total of 24 states providing lane width guidance. The range varied from 3.05 to 4.27 meters (10 to 14 feet), with 3.35 meters (11 feet) being the most common standard. Several states provided detailed requirements on lane width minimums depending on shoulder width. Six states were found to have a lane width requirement taking the shoulder into consideration. For example, in New Mexico the minimum lane width in the absence of a shoulder is 3.66 meters (12 feet), and with a minimum 0.61 meter ( 2 foot) shoulder, the minimum lane width is 3.35 meters ( 11 feet).

\section{ReseARCH Methodology}

The first step was a complete literature review of the policies, standards, and procedures of all 50 states regarding the implementation of CLRS. The standards and policies were searched in each state's Department of Transportation website. It was assumed that each state had this information available on their websites when they were access in February 2015. Much care was taken to search for the latest revised versions of their policies and standards. These standards were compared nationwide and to the characteristics of PR-114. Another key step included an evaluation of the crashes that occurred on the roadway, within the length treated with CLRS.

Another important part of the research was the observational study which entailed a site visit to PR-114 within the segment treated with CLRS between kilometers 7.6 and 14.6. The site was traveled several times, noting the very important elements in the characterization of the road function and its users. Several of the elements included: lane width, driveway density, roadside vegetation, roadside appurtenances, signs, lighting, road user type, vehicle mix, among others. Information not available from visiting the site was obtained through interviews with the engineers, construction and safety officials from the Puerto Rico Highway and Transportation Authority, The Traffic Safety Commission, and The Department of Transportation and Public Works which played an integral part to the project. In one of the interviews, a copy of the design plans were obtained. Finally, conclusions, recommendations, and suggestions for future work were made. The research methodology is shown in Fig. 5. 


\section{RESEARCH METHODOLOGY}

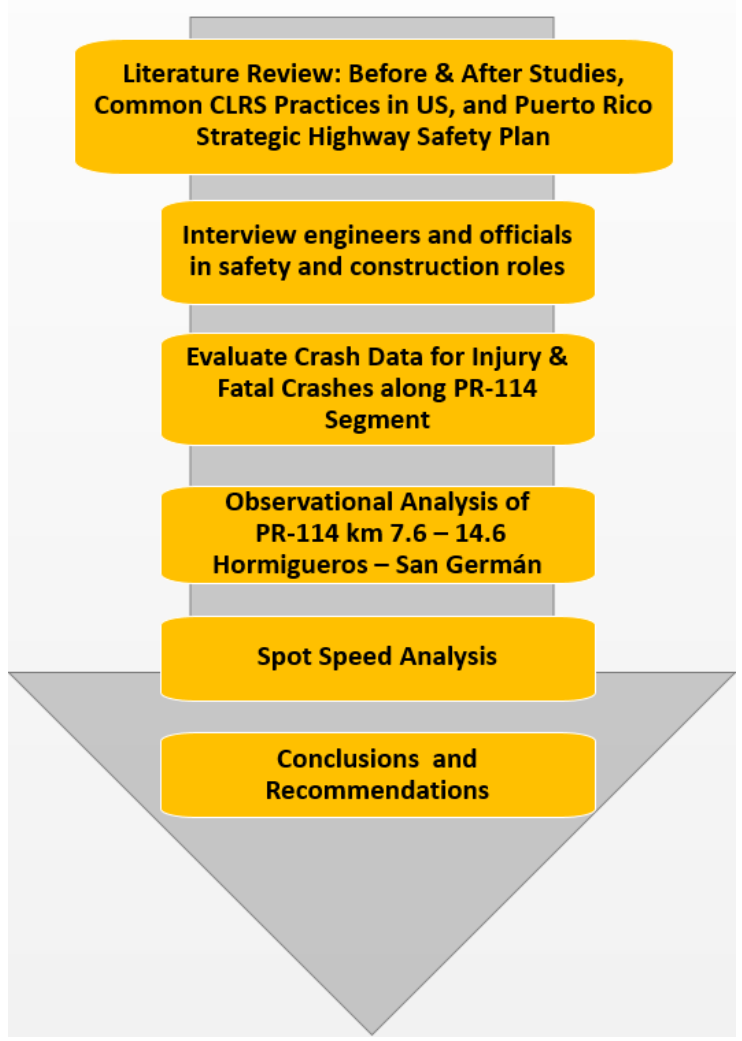

Fig. 5 Research Methodology

\section{OBSERVATIONAL ANALYSIS}

The Commonwealth of Puerto Rico, a territory of the United States, is an archipelago situated east of the Dominican Republic and west of the U.S. Virgin Islands in the Caribbean Sea. The Island measures 177 kilometers (110 miles) long by 63 kilometers (39 miles) wide and consists of 9,000 square kilometers (3,345 square miles) with approximately 26,866 kilometers $(16,694$ miles) of highway to service the population of approximately 3.7 million people. The average rainfall rate is $175 \mathrm{~cm}$ (69 in) per year [4]. The roadway PR-114 is located on the southwestern portion as shown in Fig. 6. PR-114 starts at the intersection of PR-2 and Corazones Avenue in the Municipality of Mayagüez, and ends at the intersection with PR-102 in the Municipality of San Germán. The PR-114 rural road also provides access to the municipalities of Hormigueros and Cabo Rojo.

The observational analysis took place in the afternoon of February 13, 2015. The segment chosen for this project began on $\mathrm{km} \mathrm{7.6,} \mathrm{near} \mathrm{the} \mathrm{intersection} \mathrm{with} \mathrm{PR-319,} \mathrm{and} \mathrm{ended} \mathrm{at} \mathrm{km}$ 14.6, near the intersection with PR-102 with a posted speed limit of $56 \mathrm{~km} / \mathrm{hr}(35 \mathrm{mi} / \mathrm{hr})$. Within this stretch there were approximately 25 driveways of which about half were hidden, varying from gas stations to residential housing to water and sewer authority facilities. Approximately 90 percent of these driveways were unpaved and several were located within a horizontal curve which creates a potential hazardous condition especially in the case where a vehicle needs to accelerate from the driveway to the main highway. There was a variability in driveway widths, paved versus unpaved, and level of illumination in the vicinity of the driveway. Fig. 7 depicts an unpaved driveway with limited sight as a result of high roadside vegetation and a utility pole.

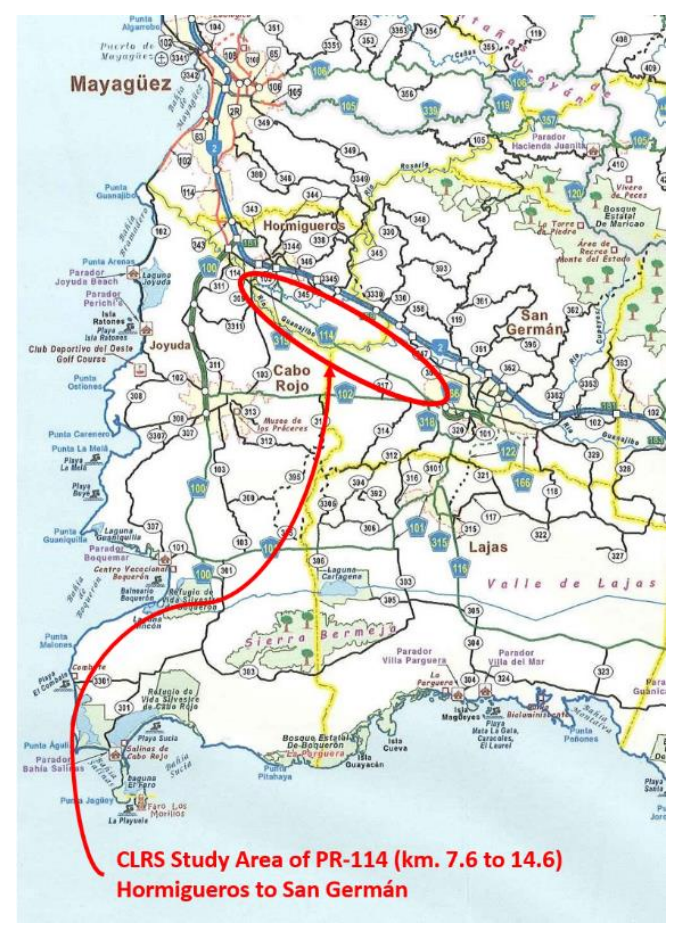

Fig. 6 PR-114 Study Area - Km 7.6 - 14.6 Hormigueros to San Germán, PR

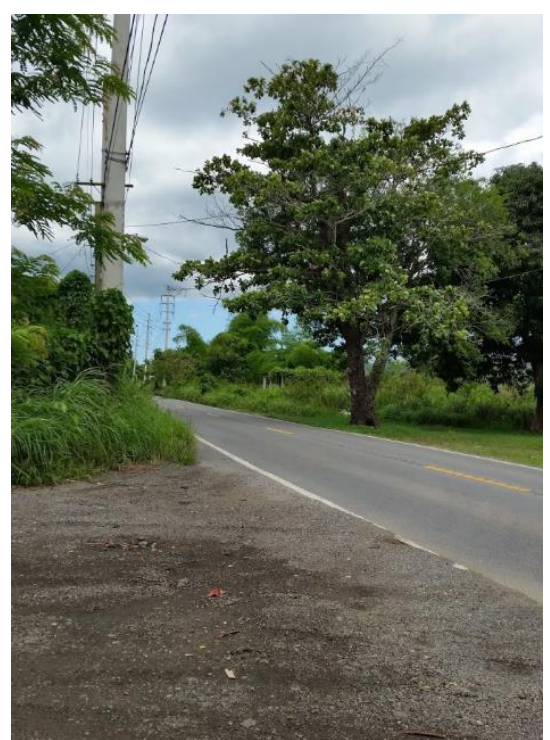

Fig. 7 Unpaved Driveway View from Driver's Line of Sight, Km 9.5 
This route contains a high volume of vehicles within the morning of the week days for several reasons. The roadway offers linkage between the four municipalities mentioned to a mix of road users such as: passenger cars, SUVs, motorcycles, equestrians, cyclists and heavy vehicles. Examples of road users other than passenger cars that are frequently found on the highway are shown. Fig. 8a and 8 b depict examples of road users other than passenger cars that are frequently found on the highway.

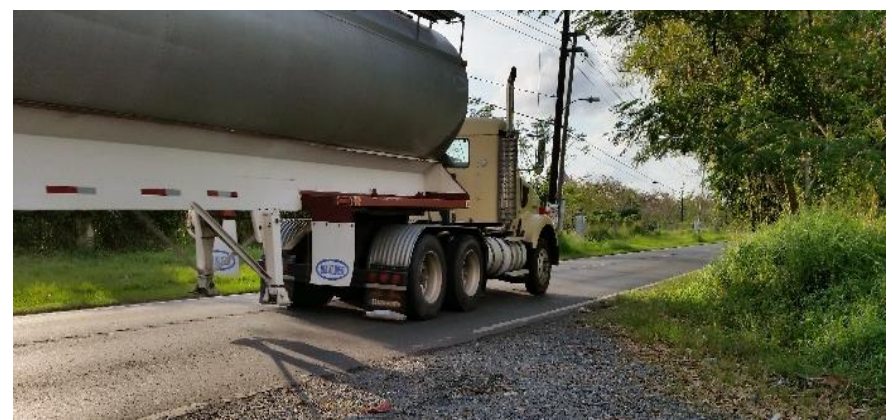

a) Tractor Semi-Trailer Tanker Truck with 350 Ton (10,000 Gal.)

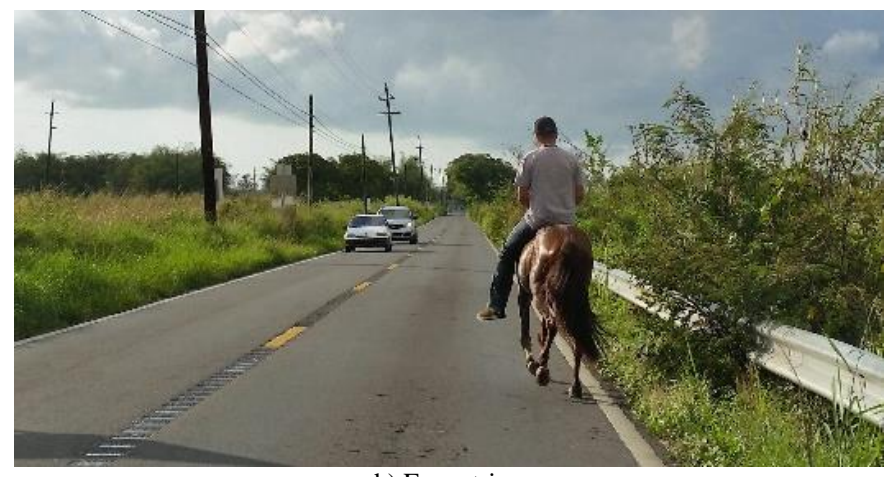

b) Equestrian

Fig. 8 Road User Mix

This road serves as an alternative route to the National Highway System (NHS) PR-2. The increase of population of these municipalities, with traffic generators that includes universities, medical facilities, malls, and shopping centers has made this alternative corridor popular to a variety of road users to avoid traffic congestion on PR-2 during peak hours. InterAmerican University of San Germán is one of the largest traffic generators due to its close proximity to the highway, approximately a kilometer away from the intersection of PR102 and PR-114. The large proportion of university student commuters are characteristic of the road user mix. Another principal generator is a company known as "Cabo Rojo Gas" at the intersection of PR-319 and PR-114 kilometer 7.0, which produces a large quantity of heavy vehicle traffic.

Based on the combination of the current geometry, essential long tangents, and generally higher percentage of younger drivers, the current $56 \mathrm{~km} / \mathrm{hr}(35 \mathrm{mi} / \mathrm{hr})$ speed limit is not obeyed with over 50 percent violations observed in the study period. The disregard to the speed limit is also evident in the number of vandalized posted speed limit signs. An example is shown in Fig. 9 where the sign was spray painted to show an "86" miles per hour speed limit. One can conclude that users disagree with the posted speed limit.

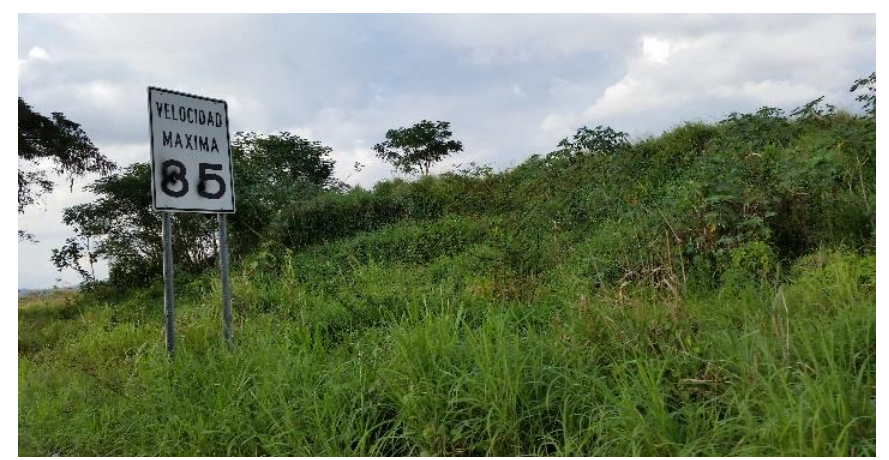

Fig. 9 Speed Limit Sign Vandalism along PR-114.

The segment is a rural two-way, two-lane segment with an estimated lane width varying from 2.75 to 3.05 meters ( 9 to 10 feet) with unpaved or narrow shoulders. There are five bridges, two of which are narrow bridges without prior warning signage and no centerline dividing each lane since each lane width is less than 2.75 meters ( 9 feet). The narrow bridge located on kilometer 12.0 can be seen depicted in Fig. 10a. The change is lane width can be appreciated when compared to the cross section in Fig. 10b. Fig. 10c provides a cross section along a horizontal curve on PR-114. 


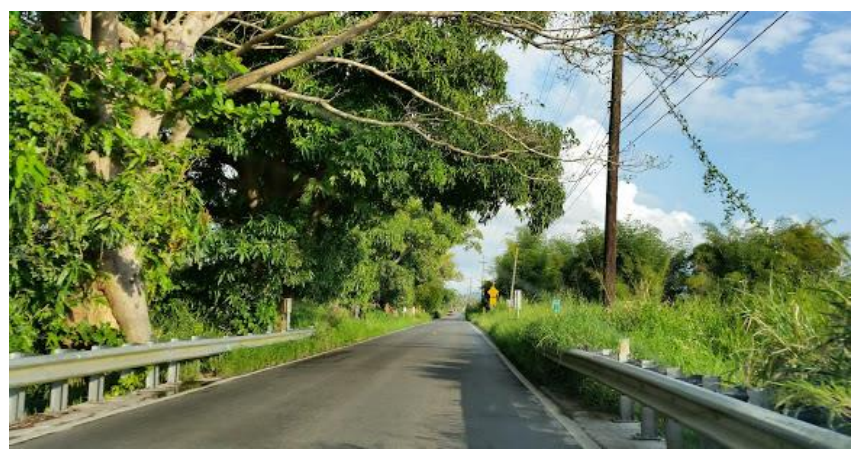

a) Narrow Bridge Km. 12.0 Eastbound

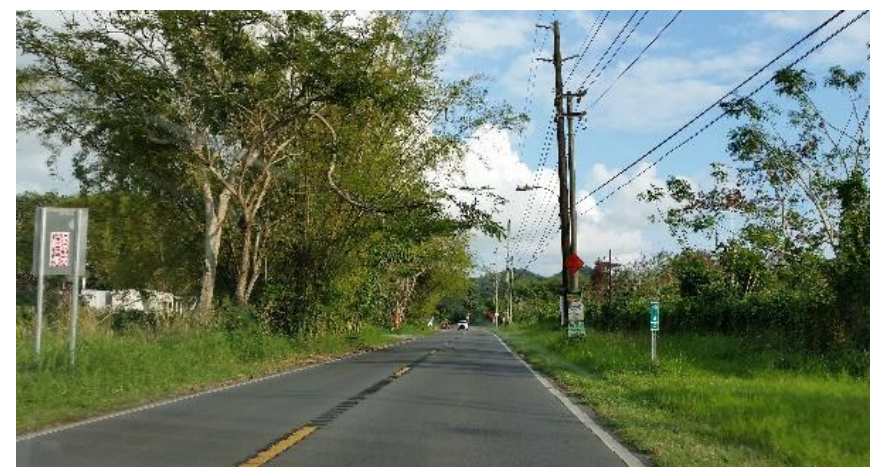

b) Cross Section Km. 14.4 Eastbound

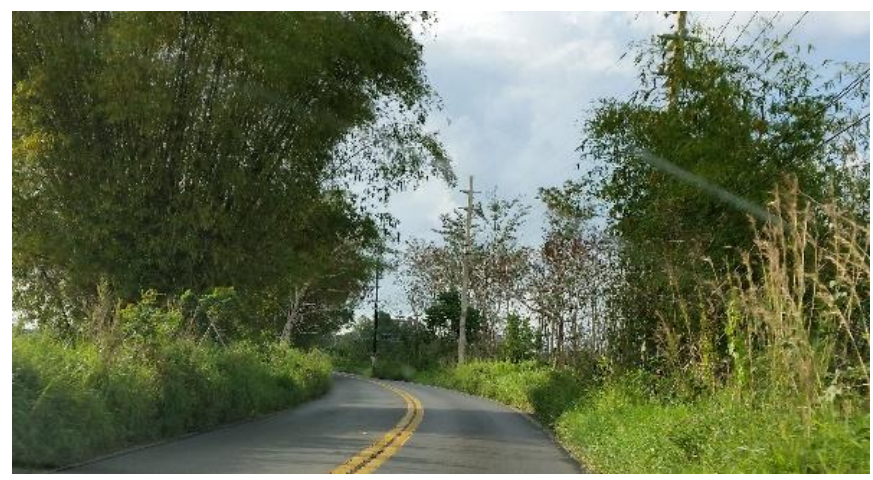

c) Cross Section on Horizontal Curve Km. 9.1 Westbound

Fig. 10 Typical Cross Sections along PR-114 Segment Treated with CLRS.

Approximately a total of 550 meters $(1,805$ feet $)$ of strong post guardrails were installed non-continuously and are found along narrow bridges and certain segments where the lateral slope or other hazardous fixed objects are located. Based on the observations, the majority of the guardrails were covered with vegetation, as shown in Fig. 11a, as well as signs, Fig. 11b, and fire hydrants. The roadside vegetation consisted of a tall grass and bamboo, vines, and trees. The trees and bamboo have managed to create a canopy along several portions of the roadway, Fig. 11c.

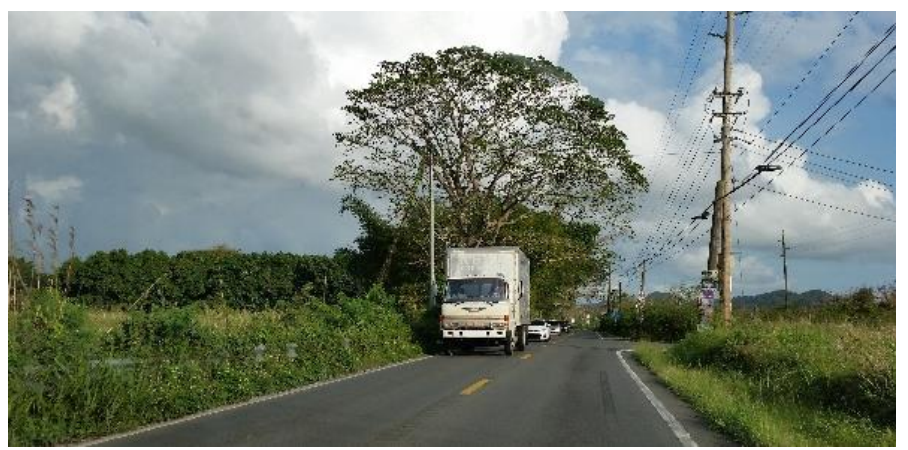

a) Guardrail Covered in Vegetation, Km. 12.7

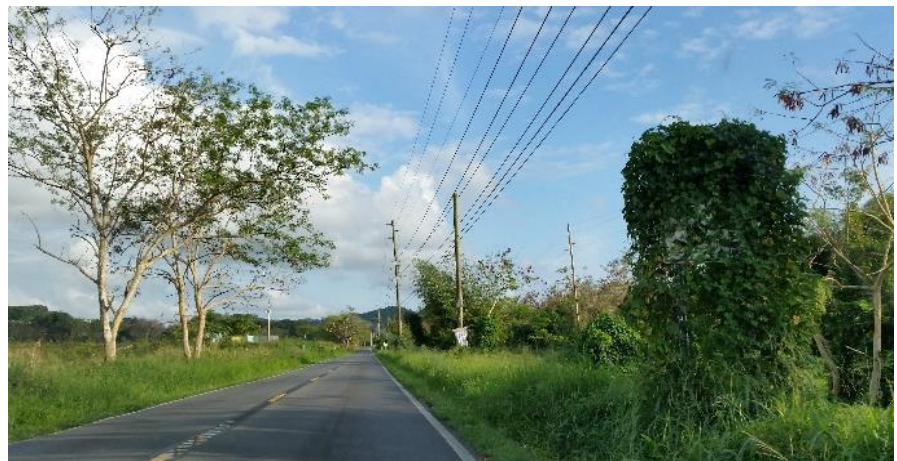

b) Speed Limit Sign Covered in Vegetation Km. 13

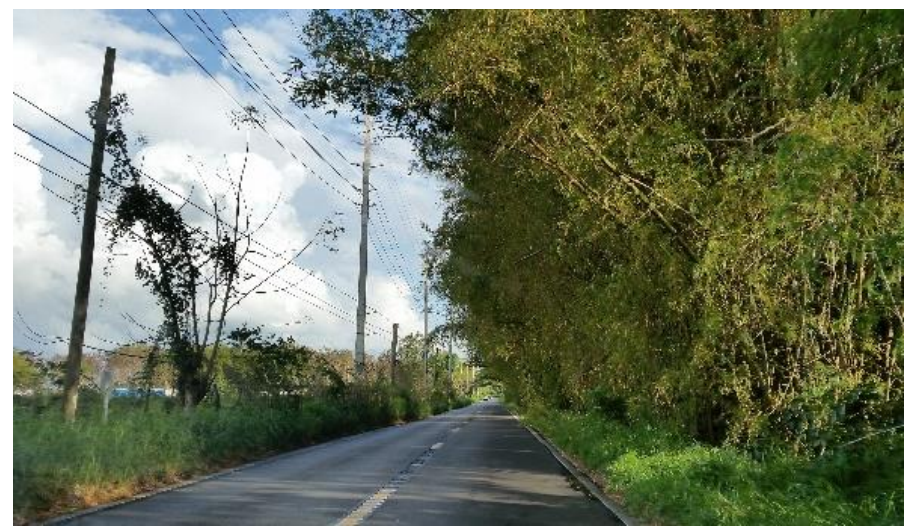

c) Tall Bamboo \& Grass Km. 9.2

Fig. 11 Typical Roadside Vegetation Issues

13 $^{\text {th }}$ LACCEI Annual International Conference: "Engineering Education Facing the Grand Challenges, What Are We Doing?" July 29-31, 2015, Santo Domingo, Dominican Republic 


\section{CONCLUSIONS}

The CLRS installed along PR-114 seem to be in agreement with the majority of the states in regards to the dimensions of the rumbles themselves. In the case of other characteristics there are variations. For instance, the posted speed limit of PR114 is $56 \mathrm{~km} / \mathrm{hr}(35 \mathrm{mi} / \mathrm{hr})$, however 36 percent of the states have a 72 or $80 \mathrm{~km} / \mathrm{hr}$ ( 45 or $50 \mathrm{mi} / \mathrm{hr}$ ) minimum posted speed requirement. Eighty percent of the PR-114 road users were exceeding the speed limit. During the site visit, when driving along the road the posted speed limit, a platoon of cars would pass on the left.

In regards to lane width, when comparing to the practices in the states, the roadway does not meet the majority of the states' standards with its 2.7-3.0 meter (9-10 foot) lanes. The majority $(>50 \%)$ of the states that had a lane width practice, required 11 feet and some even wider in the case of unpaved shoulders. The majority of PR-114 has narrow or unpaved shoulders which are covered by high vegetation that give the driver the perception of a narrower roadway. In the case of the minimum ADT, the treatment segment of PR-114 meets and exceeds all of the requirements practiced in the states, with its ADT of approximately $12,000 \mathrm{vpd}$.

Other policies or standards found practiced in the states included provisions about vehicle mix. One state does not recommend CLRS installation along roads with high horse and buggy traffic. Although Puerto Rico does not have horse-drawn buggy traffic, the common equestrian traffic is a factor in the safety of the roadway after CLRS implementation. Another provision, a pavement requirement, was found only in 15 states. This majority of these provisions asked for a pavement in "good condition", however due to the relative nature of this description, the standard is open to interpretation. In the case of Puerto Rico, CLRS are currently only being considered in new pavement applications.

Although the CLRS safety treatment has been in place for less than two years' time, there has already been a reduction in fatal and total crashes. It is possible that the CLRS are not fully responsible for the reduction, due to other possible contributing factors, but it can be concluded that there is a reduction since 2007. The crash statistics including total crashes and fatal crashes are depicted in Fig. 12.

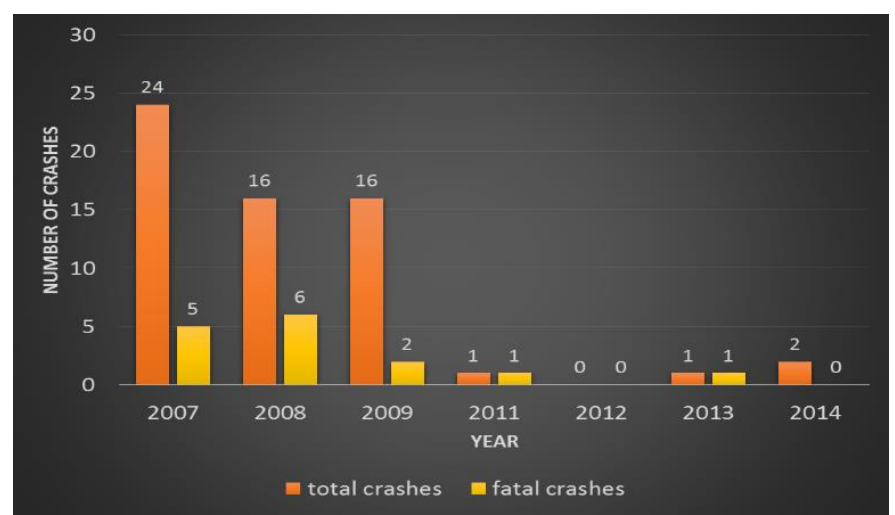

Fig. 12 Total \& Fatal Crash Statistics Within Treated Segment of PR-114, Data Source: Mayagüez Regional Police Crash Reports

This technical paper provides a first attempt to introduce CLRS as a potential cost effective safety countermeasure on two-lane rural highways in a tropical setting in Puerto Rico. The definitions, CLRS construction methods, as well as advantages and disadvantages are discussed. Furthermore the findings of the observational studies conducted on the first experimental CLRS constructed in Puerto Rico on PR-114, in between the municipalities of Hormigueros and San Germán are discussed.

\section{RECOMMENDATIONS \& FUTURE WORK}

Short and mid-term recommendations for the expansion of this treatment on our rural network on the island are presented as well as other techniques to better analyze the human component on this type of treatment in rural settings.

The current speed limit on PR-114 seems low for a rural road. Further research will include a spot speed analysis to evaluate driver behavior and obtain mean speeds. In locations where there are hidden driveways and narrow bridges, an advanced warning sign would be beneficial to the driver. It would have been preferable to have wide paved shoulders, which are mostly less than 1.2 meters ( 4 feet) in width. Another viable option would be wider lanes. This way, drivers will be less inclined to drive near the centerline, and then reduce the probability of premature pavement deterioration around the rumbles or along the edge of pavement. Future research of maximum traffic volumes for CLRS applications would also be of interest. It is important to ask the question at what point are there too many vehicles on the road that the use of the CLRS are no longer warranted.

\section{ACKNOWLEDGMENT}

The authors would like to acknowledge the Engineer Juan Carlos Rivera from the Puerto Rico Highway and Transportation Authority, Engineer Edgar Enríquez from the Puerto Rico Department of Transportation and Public Works, Ismael Vargas from the Puerto Rico Traffic Safety Commission, and the Engineer José R. González. 


\section{REFERENCES}

[1] Persaud, Bhagwant N., Retting, R.A., and Lyon, C.A., "Crash Reduction Following Installation of Centerline Rumble Strips on Rural Two-Lane Roads", Accident Analysis and Prevention 36, 2004, pp. 1073-1079.

[2] NHSTA National Center for Statistics and Analysis, "Traffic Safety Facts: 2010 Data - Rural/ Urban Comparison,” Washington, D.C., DOT HS 811 637, July 2012.

[3] NHTSA National Center for Statistics and Analysis, "Traffic Safety Facts: Research Note," Washington, D.C., DOT HS 812 101, December 2014.

[4] Puerto Rico Department of Transportation and Public Works "2014 - 2018 Puerto Rico Strategic Highway Safety Plan", San Juan, Puerto Rico, July 2014.

[5] Federal Highway Administration Technical Advisory, "Centerline Rumble Strips", T 5040.40, Revision 1, November 7, 2011.

[6] Kusano, Kristofer D. and Gabler, H. C. "Characterization of OppositeDirection Road Departure Crashes in the United States", Transportation Research Record: Journal of the Transportation Research Board, No. 2377, Transportation Research Board of the National Academies, Washington, D.C., 2013, pp. 14-20.

[7] http://www.nhtsa.gov/FARS

[8] NCHRP Synthesis 339, "Centerline Rumble Strips: A Synthesis of Highway Practice", National Cooperative Highway Research Program, Transportation Research Board of the National Academies, Washington, D.C., 2005.

[9] NCHRP Report 641, "Guidance for the Design and Application of Shoulder and Centerline Rumble Strips", National Cooperative Highway Research Program, Transportation Research Board, Washington, D.C. 2009.

13 $^{\text {th }}$ LACCEI Annual International Conference: "Engineering Education Facing the Grand Challenges, What Are We Doing?" 